\title{
KONSEP AJA WERA \\ SEBAGAI MODEL PEMBELAJARAN ESOTERIK \\ PADA UMAT HINDU DI BALI
}

\author{
Oleh : \\ I Gusti Ketut Widana \\ Dosen Fakultas Pendidikan Agama dan Seni UNHI \\ igustiketutwidana1805@gmail.com
}

\begin{abstract}
ABSTRAK
Konsep Aja Wera telah sejak dulu dikenal masyarakat Bali dan dianggap sebagai bentuk "larangan" mempelajari, mendalami atau menguasai pengetahuan/ajaran agama Hindu. Itulah sebabnya mengapa umat Hindu untuk urusan belajar agama, dengan segala konsep ajaran, atau kandungan makna tattwanya nyaris tidak begitu dipedulikan. Berbeda dengan urusan aktivitas ritual yadnya, umat Hindu begitu semangat dan bergairah menjalankannya, meski tidak ditunjang pengetahuan yang melandasi pelaksanaan ritual yadnya tersebut. Pegangannya adalah adagium gugon tuwon bin anak mulo keto, dengan prinsip melaksanakan kewajiban ritual yadnya dengan patuh tanpa perlu tahu apa makna tattwa dibaliknya.
\end{abstract}

Kata Kunci: Aja Wera, Model Pembelajaran, Esoterik

\section{ABSTRACT}

The concept of Aja Wera has long been known to the people of Bali and is considered as a form of "prohibition" to learn, explore or master the knowledge / teachings of Hinduism. That is why Hindus for religious learning affairs, with all the concepts of teaching, or the content of the meaning of tattwa are hardly cared for. In contrast to the affairs of the yad ritual activities, Hindus are so passionate and passionate about carrying out them, even though they are not supported by the knowledge underlying the yadnya ritual. The handle is adagium gugon tuwon bin anak mulo keto, with the principle of carrying out the ritual obligations of the yad in obedience without needing to know what the tattwa means behind it. Keywords: Aja Wera, Learning Model, Esoteric

\section{PENDAHULUAN}

Kitab suci agama Hindu adalah Weda (Veda), berasal dari urat kata "Wid" (Vid) yang mengandung arti "pengetahuan". Sebagai pengetahuan, keberadaan Weda tentunya wajib diketahui dengan cara mempelajarinya. Tanpa proses belajar, apapun pengetahuan itu, lebih-lebih pengetahuan rohani (spiritual) jelas tidak akan dapat dimengerti, dipahami, didalami, dihayati apalagi dikuasai. Diperlukan hasrat, niat dan semangat belajar untuk menguasai pengetahuan agama, sebagaimana disuratkan di dalam kitab suci Bhagawadgita, IV. 34 :

tad viddhi pranipatena
pariprasnena sevaya
upadekshyanti te jnanam
jnaninas tattvadarsinah
"pelajarilah itu (agama) dengan sujud
disiplin, dengan bertanya dan kerja
berbhakti; orang yang berilmu,
mereka melihat kebenaran, akan


mengajarkan kepadamu pengetahuan itu" (Pudja, 1981: 116)

Meskipun demikian tuntunannya, dalam realitanya umat Hindu lebih taat dan disiplin menjalankan ajaran agamanya, terutama yang berkaitan dengan ritual yadnya. Sehingga, walaupun relatif tidak menguasai landasan tattwa-jnananya, seperti teologi dan filosofinya, kebanyakan umat Hindu merasa mantap dan penuh keyakinan melaksanakan kewajiban ritualnya. Sampai kemudian dikatakan, umat Hindu melaksanakan ajaran agamanya, khususnya dalam bentuk ritual hanya berdasarkan pakem 'gugon tuwon', yang biasanya disertai anak kalimat 'nak mulo keto' (memang sudah demikian adanya).

Belum lagi adanya semacam "tekanan" psikologis yang sejak dulu mendoktrin umat Hindu melalui ungkapan Aja Wera (aywa wera), yang ditafsir sebagai bentuk "larangan/pantangan" mempelajari atau mendalami ajaran agama melalui bacaan kitab-kitab suci, termasuk yang berupa lontar-lontar. Jika larangan itu dilanggar, konon katanya mula-mula yang bersangkutan akan mengalami perasaan “inguh" (galau), kemudian apabila dibiarkan lama-lama bisa "buduh" (gila). Bahkan, meskipun misalnya umat merasa bisa, setidaknya sudah mengetahui, lebihlebih menguasai konsep-konsep ajaran agama, biasanya selalu diingatkan lagi untuk bersikap "eda ngaden awak bisa, depang anake ngadanin" (jangan merasa diri bisa/mampu, biarkan orang lain yang mengatakan/menilai).

Berbicara konsep Aja Wera, memang acapkali dijumpai di dalam kitab-kitab, terutama pustaka lontar yang banyak memuat ajaran agama, dan dapat disebut sebagai adagium "gugon tuwon", karena mengandung makna menggugu (memercayai) nasihat (piteket) orang tua (anak tuha, nak tua, wong tuwo, tuwon), tanpa harus banyak bertanya-tanya lagi. Umat tinggal melaksanakan saja sebagai bentuk "imperatif" (perintah) orang yang dituakan, dan tidak perlu menyanggah ataupun membantah, apalagi sampai marahmarah. Sebab sebagai Guru Rupaka (orang tua), apapun yang dinasihati diyakini benar adanya, dengan asumsi tidak mungkin orang tua akan menyesatkan jalan pikiran, bahkan jalan kehidupan anak-anaknya.

Piteket 'gugon tuwon' melalui konsep Aja Wera inilah yang sebenarnya semakin menjadikan umat Hindu bersikap "cuek", merasa tidak perlu mempelajari, mengetahui, memahami, menghayati, apalagi mendalami serta menguasai ajaran agama, yang sebagian diantaranya memang bersifat esoteris (rahasia). Alasan klasiknya, untuk apa mempelajari ajaran agama, bukankah sudah ada pihak yang membidangi dan menguasai perihal tattwa-jnana beragama, 
termasuk tentang pelaksanaan ritual yadnya, yang secara historis tradisional disebut golongan Brahmana atau pihak Geriya.

Tampaknya, konsep Aja Wera dalam paradigma pendidikan kekinian, bisa dinilai sebagai "pembodohan", karena dianggap menghalangi, sekaligus membiarkan umat Hindu berada dalam kegelapan pengetahuan (awidya) atau bodoh (punggung). Persoalannya sekarang, jika konsep Aja Wera ini dibiarkan tanpa reinterpretasi dan aktualisasi kekinian, bukan tidak mungkin ke depannya, lebih-lebih di tengah era teknologi dan informasi digital, ajaran agama Hindu, jangankan yang bersifat esoteris (rahasia), yang berisi tuntunan praktis dalam menjalankan kewajiban beragama pun bisa ditinggalkan, bahkan keyakinan Hindu sebagai agamanya bisa juga ditanggalkan.

Melalui pengkajian secara implisit, konsep Aja Wera sebenarnya justru menstimulus umat agar giat dan semangat mempelajari, mengkaji dan mendalami ajaran Hindu, baik yang berada di tataran pengetahuan agama tingkat tinggi (parawidya/nirwirti/niskala) pengetahuan agama level bawah (aparawidyalprawrti/sakala).

Hanya saja, karena tergolong esoterik (rahasya jnana), konsep Aja Wera mensyaratkan pentingnya kehadiran sosok guru pembimbing agar tidak salah dalam mencerna ataupun menafsirkan ajaran dimaksud, yang dikhawatirkan bisa menjerumuskannya pada kesesatan pikiran dan keyakinan. Begitu pula manakala umat sudah mulai mengetahui, bisa memahami, dan mampu mendalami, selalu diingatkan untuk tidak mabuk atau sombong lantaran merasa telah pintar menguasai ajaran agama, sebab bisa menjerumuskannya pada kesesatan.

\section{II.PEMBAHASAN}

\section{Mencermati Konsep}

Mencermati judul artikel ini, terlebih dahulu dideskripsikan beberapa konsepnya. Dimulai dari pengertian Aja Wera yang terdiri atas dua kata ; "Aja" yang dalam bahasa Kawi berarti "jangan", dan "Wera" berarti “mabuk" (Antara, dkk, 2009: 8, 823). Jadi, kata Aja Wera atau berarti jangan mabuk, apalagi sampai bertingkah gila-gilaan (inguh/mamuduh). Makna yang dikandung dalam konsep Aja Wera ini adalah sebagai untunan atau arahan bahwa tatkala hendak belajar pengetahuan agama hendaknya dilakukan dengan sungguh-sungguh (seken), dispilin, dan kemudian tidak sombong, atau takabur, tetaplah bersikap rendah hati, jangan sekali-kali merasa diri bisa (dueg/ririh), berlakulah seperti ilmu padi, semakin berisi semakin merunduk.

Konsep berikutnya adalah 'model pembelajaran', berasal dari kata "model" /mo-del/ $n$ menghandung arti "pola" (contoh, acuan, ragam, macam, dan sebagainya) 
(Poerwadarminta, 1986: 653). Sedangkan arti kata "pembelajaran" (pem-bel-ajar-an) adalah proses, cara, perbuatan menjadikan orang atau makhluk hidup belajar (https://jagokata.com>arti-

kata>pembelajaran). Sementara itu menurut Joyce dan Weil (dalam Sumaryono, 2012: 133), model pembelajaran adalah suatu rencana atau pola yang dapat digunakan untuk membentuk kurikulum (rencana pembelajaran jangka panjang), merancang bahan-bahan pembelajaran, dan membimbing pembelajaran di kelas atau yang lain. Model pembelajaran dapat dijadikan pola pilihan, t artinya para guru boleh memilih model pembelajaran yang sesuai dan efisien untuk p mencapai tujuan pendidikannya.

Dikaitkan dengan artikel ini, Mengkaji Konsep Aja Wera Berdasarkan tampaknya konsep Aja Wera, meski tidak Teori populer bahkan sampai saat ini maih dianggap sebagai bentuk "larangan" belajar pengetahuan agama, tetapi sesungguhnya dibalik Aja Wera itu terkandung stimulus agar umat disiplin belajar. Terutama ketika mempelajari pengetahuan agama, apalagi yang bersifat esoterik (rahasia) dan bahkan disakralkan (tenget), perlu menunjukkan sikap dan perilaku yang jauh dari kesombongan, atau tidak mabuk karena penguasaan pengetahuan, lalu berperilaku gila-gilaan, yang sangat bertolak belakang dengan pitutur ayu "eda ngaden awak bisa, atas pertanyaan-pertanyaan dalam rumusan depang anake ngadanin”.

Selanjutnya konsep 'esoterik' (esoteric, Inggris) /ks, berarti "hanya diketahui dan dipahami oleh beberapa orang tertentu saja" (Echols dan Shadily, 2002: 218). Kata esoterik ini juga diartikan sebagai sesuatu yang bersifat rahasia, tidak boleh diumbar penyampaiannya, apalagi berkaitan dengan pengetahuan agama Hindu dengan ajaranajarannya yang bersifat esoterik (rahasya jnana) dan tergolong parawidya (pengetahuan rohani), sehingga tidak boleh sembarangan mempelajari dan menguasainya, kecuali dengan tuntunan/bimbingan guru suci/spiritual. Gunanya untuk menghindari kesesatan, baik pikiran, ucapan, tindakan dan keyakinannya. Teori merupakan informasi ilmiah yang di dapat dengan cara meningkatkan abstraksi pengertian maupun hubungan proposisi. Teori menunjukkan hubungan antara fakta-fakta. Fakta didapat atau dibuktikan secara empiris. Teori berfungsi mengarahkan perhatian atau untuk menerangkan, merangkum pengetahuan, meramalkan fakta dan memeriksa gejala (Usman dan Akbar, 2008 : 7).

Untuk menajamkan analisis dalam menyingkap sekaligus mengungkap jawaban 
masalah di atas, penelitian ini menggunakan teori :

\section{1) Teori Simbol}

Teori simbol dicetuskan Filsuf Susanne K. Langer, lahir di Manhattan, 20 Desember 1895 yang terkenal dengan karyanya "Philosophy in a New Key" yang berbicara tentang bagaimana simbol memengaruhi pemikiran manusia menjadi kebutuhan untuk mengekspresikan diri. Secara etimologis istilah "simbol" diserap dari kata "symbol" dalam bahasa Inggris yang berakar pada kata "symbolicum" dalam bahasa Latin. Sementara dalam bahasa Yunani disebut "symbolon" atau "symballo", yang juga menjadi akar kata "symbol", dengan beberapa makna generik, yaitu : “memberi kesan", "berarti" dan "menarik".

Berdasar sejarahnya, simbol memiliki dua pengertian yang sangat berbeda. Dalam pemikiran dan praktik keagamaan, simbol lazim dianggap sebagai pancaran Realitas Transenden. Dalam sistem pemikiran logika dan ilmiah, istilah simbol lazim dipakai dalam arti tanda abstrak. Adapun beberapa pengertian "simbol" adalah :

(a) Simbol adalah sesuatu yang biasanya merupakan tanda yang terlihat yang menggantikan gagasan atau objek.

(b) Simbol adalah kata, tanda, atau isyarat yang digunakan untuk mewakili sesuatu yang lain seperti arti, kualitas, abstraksi, gagasan, dan objek.

(c) Simbol adalah apapun yang diberikan arti dengan persetujuan umum dan atau dengan kesepakatan atau kebiasaan.

(d) Simbol sering diartikan secara terbatas sebagai tanda konvensional, sesuatu yang dibangun oleh masyarakat atau individu dengan arti tertentu yang kurang lebih standar dan disepakati atau dipakai anggota masyarakat itu sendiri. Arti simbol dalam konteks ini sering dilawankan dengan tanda ilmiah.

Teori Simbol yang dicetuskan Susanne K. Langer ini dinilai bermanfaat karena mengemukakan sejumlah konsep dan istilah yang biasa digunakan dalam ilmu komunikasi. Menurut Langer, kehidupan binatang diatur oleh perasaan (feeling), tetapi perasaan manusia diperantarai oleh sejumlah konsep, simbol, dan bahasa. Binatang memberikan respons terhadap tanda, tetapi manusia membutuhkan lebih dari sekadar tanda, manusia membutuhkan simbol. Langer memandang makna sebagai sebuah hubungan kompleks di antara simbol, objek dan manusia yang melibatkan denotasi (makna bersama) dan konotasi (makna pribadi).

Triguna (2000 : 7) menambahkan bahwa simbol adalah satu hal atau keadaan yang merupakan pengantaraan pemahaman 
terhadap objek. Manifestasi karakteristik simbol tidak terbatas pada isyarat fisik, tetapi dapat juga pada berwujud penggunaaan katakata, yakni simbol suara yang mengandung arti bersama serta bersifat standar. Singkatnya simbol berfungsi memimpin subjek kepada objek.

Prinsip kerja teori simbol ini adalah : 1) Manusia mempelajari simbol dan makna di dalam interaksi sosial; 2) Manusia menggapai tanda-tanda dengan tanpa berpikir, sebaliknya, mereka menanggapi simbol dengan cara berpikir, dan 3) Tanda-tanda mempunyai artinya sendiri. Dengan kata lain Charon (dalam Ritzer, 2007 : 292) menyimpulkan, simbol adalah objek sosial yang dipakai untuk merepresentasikan atau menggantikan apapun yang disetujui orang yang akan mereka representasikan.

Penggunaan teori simbol dalam penelitian ini diarahkan untuk menelaah atau membedah tentang makna dibalik simbol, terutama dalam konsep Aja Wera, yang tidak sekedar tampak sebagai penanda kultural, tetapi lebih kepada ungkapan leksikal berbasis sradha (keyakinan) dengan orientasi ke arah peningkatan kualitas intelektual (jnana) umat Hindu. Sehingga dalam praktik keagamaan, tidak terus terjebak pada gugon tuwon anak mulo keto, yang menyebabkan umat Hindu tetap terkungkung pada keadaan awidya (ketiadaan pengetahuan/kebodohan).
Ternyata konsep Aja Wera, merupakan bentuk simbol yang dicetuskan melalui ungkapan (kata/bahasa) yang mengandung makna bahwa ajaran agama Hindu bukan tidak boleh dipelajari, dikaji atau didalami, tetapi justru mendorong peningkatan pengetahuan umat dengan cara giat belajar agama, dengan tetap mematuhi rambu-rambunya agar tidak mabuk ataupun sombong ketika sudah menguasainya.

\section{2) Teori Hermeneutik}

Teori Hermeneutik dalam penelitian ini menggunakan pandangan F.D.E Schleiermacher, yang dilahirkan di Breslau pada tanggal 21 November 1768 dan meninggal 12 Februari 1834. Schleiermacher menggunakan bidang Hermeneutik terutama dalam diskusi-diskusi tentang filsafat dan teologi. Secara etimologis, kata "Hermeneutik" berasal dari bahasa Yunani "Hermeneuein" yang berarti 'menafsirkan', "penafsiran" atau interpretasi.

Bidang Hermeneutik diartikan sebagai 'proses mengubah sesuatu atau situasi ketidaktahuan menjadi mengerti'. Batasan umum ini selalu dianggap benar, baik hermeneutik dalam pandangan klasik maupun dalam pandasngan modern (Palmer, 1969 : 3). Hermeneutik dalam pandangan klasik akan mengingatkan pada apa yang ditulis Aristoteles dalam "Peri Hermeneias" atau "De Interpretatione", bahwa kata-kata yang diucapkan adalah simbol dari 
pengalaman mental, dan kata-kata yang menentukan keberhasilannya dalam bidang ditulis adalah simbol dari kata-kata yang seni interpretasi.

diucapkan itu (Sumaryono, 1999: 24).

Schleiermacher menawarkan sebuah

Penerapan Hermeneutik sangatlah luas, rumusan positif dalam bidang seni yaitu dalam bidang teologis, filosofis, interpretasi yaitu rekonstruksi historis, linguistik maupun hukum. Secara dasariah objektif dan subjektif terhadap sebuah Hermeneutik adalah filosofis, sebab pernyataan, tak terkecuali ungkapan lewat merupakan "bagian dari seni berpikir". bahasa atau kata-kata seperti halnya konsep Pertama-tama buah pikiran itu dimengerti, Aja Wera. Melalui rekonstruksi tersebut baru kemudian diucapkan. Inilah alasannya dimaksudkan agar dapat menemukan awal mengapa Schleiermacher menyatakan bahwa mulanya sebuah pernyataan (ungkapan) itu bicara menjadi berkembang seiring denganh muncul dan kemudian menjadi bagian dari buah pikiran. Namun bila pada saat berpikir pikiran kebanyakan orang. Schleiermacher merasa perlu untuk membuat persiapan sendiri menyatakan bahwa tugas dalam mencetuskan buah pikiran itu, maka Hermeneutik adalah memahami teks "sebaik pada saat itulah terdapat apa saja yang atau lebih baik daripada pengarangnya disebutnya sebagai "transformasi berbicara sendiri" dan "memahami pengarang teks yang internal dan orisinal, dan karenanya lebih baik daripada memahami diri sendiri". interpretasi menjadi penting".

Aplikasi teori Hermeneutik dalam

Prinsip kerja teori Hermeneutik mengkaji topik aretikel ini bermanfaat untuk menurut Schleiermacher ada dua, yaitu : menyingkap dan mengungkap perihal apa, interpretasi gramatikal dan interpretasi mengapa dan bagaimana konsep Aja Wera itu psikologis. Bahasa gramatikal merupakan bisa muncul, sebagai bagian dari pikiran syarat berpikir setiap orang. Sedangkan masyarakat Bali, khususnya umat Hindu interpretasi psikologis memungkinkna yang dalam proses pembelajaran agamanya seseorang menangkap 'setitik cahaya' pribadi ada yang bersifat rahasia, atau dirahasiakan. penulis. Oleh karenanya, untuk memahami Sehingga oleh sebagian besar umat Hindu pernyataan-pernyataan pembicara lewat ditafsir sebagai bentuk "larangan" (aja = ungkapan kata/bahasa, orang harus mampu jangan), akibatnya untuk urusan peningkatan memahami bahasanya sebaik memahami pengetahuan agama umat Hindu menjadi kejiwaannya. Kompetensi ilnguistik dan relatif terkebelakang, untuk tidak kemampuan mengetahui seseorang akan mengatakannya awidya/punggung alias bodoh. 
Melalui penggunaan teori Hermeneutik diharapkan terungkap tafsiran yang lebih bermakna sesuai konteks kekinian, tidak lagi terjebak dalam kesalah-pahaman atau salah tafsir kronis, dari generasi ke generasi, konsep Aja Wera tetap dianggap sebagai larangan membaca, mempelajari, memahami, keb mendalami apalagi menguasai Weda. Bahkan dengan nada menakut-nakuti bila itu dilakukan akan membuat umat yang mempelajari Weda, meski hanya membuka dan membaca lewat lontar saja dikatakan bisa inguh (galau) atau lanjut menjadi buduh (gila).

\section{Interpretasi Konsep Aja Wera}

Mengacu Turaeni (2016) dalam artikel berjudul "Mengenal Kearifan Lokal Masyarakat Bali Dalam Ungkapan Tradisi Lisan "Wewangsalan”. Turaeni mengemukakan bahwa kearifan lokal merupakan sesuatu yang berakar pada masa lalu dalam kehidupan tradisional masyarakat lokal yang dijadikan rujukan bagi tatanan kehidupan dan kebudayaan lokal. Kearifan lokal juga berarti wawasan atau cara pandang menyeluruh yang bersumber dari tradisi kehidupan. Kearifan lokal masyarakat Bali dapat dilacak dalam tradisi lisan, salah satunya dapat ditelusuri dalam wewangsalan.

Lebih lanjut Turaeni menyatakan, sastra lisan khususnya tradisi lisan dapat dijadikan media reflektif untuk mengarifi nilai-nilai budaya lokal masyarakat Bali. Sebagai salah satu bagian dari kebudayaan nasional, tradisi lisan sebagai kekuatan budaya daerah memiliki fungsi sebagai identitas dan kebanggaan daerah, serta pemersatu kedaerahan. Sebagai bagian tradisi kebudayaan daerah Bali, mengandung kearifan lokal yang berfungsi untuk memelihara integritas dan jati diri masyarakatnya.

Mengutip Effendy (2006: 6) Turaeni menambahkan, bahwa dalam pandangan masyarakat tradisional, sastra lisan (ungkapan lisan) dipandang sebagai representasi realitas atau kenyataan sesungguhnya. Dalam hal ini, sastra lisan (tradisi lisan) diyakini berkaitan dengan sejarah asal-usul suatu suku bangsa, sejarah lokal suatu tempat, entah kampung, entah kota, sejarah jatuh bangunnya suatu kerajaan, dan lain-lain.

Relevansinya dengan artikel ini menemukan titik temunya, bahwa tradisi (ungkapan) lisan seperti halnya wewangsalan, tidak berbeda jauh dengan ungkapan Aja Wera, yang sesungguhnya berasal dari tradisi tulis (teks) dalam lontarlontar yang kemudian begitu lumrah diucapkan seperti halnya tradisi lisan, yang awalnya dimaknai sebagai bentuk "larangan" belajar pengetahuan agama, meskipun sebenarnya hal itu sebagai rambu-rambu agar tidak sembarangan mempelajari, 
memahami, mendalami, dan apalagi hendak menguasai pengetahuan/ajaran

agama, terutama yang bersifat rahasia (rahasya jnana).

Hal senada dikemukakan Suyadnya (2006) dalam bukunya berjudul "Aywa Wera dan Pemahamannya" menyatakan, bahwa dalam kitab-kitab dan lontar-lontar yang memuat ajaran agama Hindu sering dijumpai kalimat pendek "aja wera" atau "aywa wera". Kalimat pendek ini adalah peringatan penulis yang artinya jangan diperluas. Maknanya agar dibatasi atau dirahasiakan. Konsepsi aywa wera, seperti pewarah Bhagawan Byasa dalam kitab Sarasamuscaya, maksudnya jangan menyalahgunakan ajaran Weda. Memang dalam ajaran Hindu ada hal-hal yang bersifat rahasia bahkan sangat rahasia yang disebut "rahasya jnana", dan untuk mempelajarinya dibutuhkan syarat-syarat tertentu sampai yang bersangkutan memiliki kondisi yang kondusif untuk menerima pelajaran itu.

Suyadnya juga menegaskan, bila halhal tersebut diajarkan secara senonoh tanpa memperhatikan syarat-syarat yang digariskan dapat menyebabkan hal-hal yang tidak diinginkan, misalnya salah persepsi sehingga terjadi orang men-Tuhankan dirinya sendiri, atau pendangkalan keimanan, tidak sopan atau gegabah, kebingungan yang serius bahkan gila dan lain sebagainya. Jadi, intinya pengetahuan agama itu memang wajib dipelajari, meskipun bersifat rahasia, sebagaimana disuratkan di dalam kitab Yajur Weda, XVI.18 :

\section{Yathenam wacam kalyaman \\ Awadani janebhyah \\ Brahma rajya nyabhyam \\ Sudraya caryaya ca sway a caranaya}

$\mathrm{ca}$

Maknanya :

Demikianlah semoga hamba dapat menyampaikan sabda suci (Weda) ini kepada masyarakat umum, kepada Brahmana, Ksatria, Waisya dan Sudra, kepada orang-orang hamba bahkan kepada orang-orang lain sekalipun

Selama ini memang telah terjadi kesalahan dalam pemahaman atau misinterpretasi terhadap konsep Aja Wera, yang begitu kuat dipahami sebagai bentuk "larangan" mempelajari ajaran agama Hindu melalui kitab suci Weda dan kitab turunannya. Bahkan adakalanya konsep Aja Wera ini juga digunakan sebagai ungkapan untuk "menakut-nakuti" umat jika berani mempelajari ajaran agama, semisal dengan menurunkan lalu membaca lontar-lontar yang memang banyak disakralkan (ditengetin), dengan mengatakan "nyanan bisa buduh" (nanti bisa gila).

Mengacu pandangan Pierre Bourdieu, salah satu modal besar yang dimiliki umat Hindu (Bali) adalah modal simbolik. Modal simbolik meliputi segala bentuk prestise, status, otoritas dan legitimasi. Khusus terkait dengan legitimasi, modal simbolik, 
merupakan upaya melestarikan dan yang berada di tingkatan kasunyatan, lebihmeningkatkan pengakuan sosial melalui lebih ilmu black magic yang bermain di reproduksi skema-skema persepsi yang tataran kesaktian(kawisesan).

paling cocok hingga menghasilkan tindakantindakan simbolik yang bahkan kemudian diwarisi turun temurun. Salah satu modal simbolik dimaksud adalah adagium "ajya wera" (haywa/aywa wera, ajya wera, aja wera), yang dalam bahasa Jawa sepertinya sepadan dengan kata "ojo dumeh". Artinya kurang lebih : "jangan mabuk" atau "jangan sombong", setelah mempelajari atau menguasai sesuatu, bisa pelajaran/pengetahuan, kemampuan, kelebihan, keunggulan, atau kekuatan.

"Aywa wera tan siddhi phalanya", begitu piteket para tetua yang artinya hendaknya jangan mabuk atau sombong oleh sebab kelebihan yang dimiliki (apapun bentuknya), karena menjadi tiada bermanfaat atau tidak berphala bagi siapapun, bahkan bisa merugikan banyak pihak. Kalau ilmu misalnya, apalagi ilmu agama yang berkaitan dengan ketuhanan transenden, yang secara permanen diyakini sebagai pondamen sraddha-bhakti, apabila dipelajari atau dipahami dan kemudian dilaksanakan dengan sembarangan/serampangan, dipercaya akan menjadi bumerang baginya. Bahkan acapkali dikatakan bisa membuat "buduh" (gila), setidaknya stres, tampak seperti orang terkena gangguan psikis lantaran belum siap diri mempelajari atau menerima ilmu agama

Sejatinya, yang membuat "buduh" itu bukan karena belum siap menerima atau menguasai ilmu dimaksud, melainkan lantaran keadaan kita yang masih "bodoh", alias tiadanya ilmu sebagai modal awal kesiapan diri menerima ilmu baru atau tambahan ilmu lain. Apalagi pada saat terjadi transfer dan transformasi ilmu tersebut selalu direspon dengan kata "badah", sebagai tanda ketidaksiapan diri menerima atau menguasai ilmu dimaksud. Dipastikan akan melahirkan "jelema matah", menguasai hanya sedikit ilmu, lalu merasa diri sudah mumpuni, lanjut diperagakan sembarangan, inilah yang dapat disebut sebagai anak punyah, bagaikan pendekar mabuk yang pastinya dapat membahayakan diri dan juga orang lain.

Khusus untuk melancarkan penguasaan ilmu Veda (kerohanian) agar tidak mabuk, telah disuratkan di dalam kitab Vayu Purana I. 201 : "Nihan paripurnekena kenaikang sanghyang Veda, makasadana iti hasa kalawan sanghyang purana, apan sanghyang Veda atakut tinukul olih wwang akidik ajinia”, maksudnya, kalau ingin menyampurnakan ilmu tentang Veda sebaiknya pelajari dan kuasai dulu itihasa (sejarah) dan purana (mitologi kuno), karena 
Veda sangat takut kalau disalahtafsirkan oleh mereka yang sedikit ilmunya (bodoh).

Merujuk jenjang pendidikan, untuk menapak ke tingkatan ilmu yang lebih tinggi, secara psikologik, metodik dan didaktik memang wajib mengikuti tahapannya, tidak ujug-ujug berhasrat atau berambisi menguasai ilmu tingkat tinggi. Bagaikan tangga, satu demi satu anak tangga keilmuan (pengetahuan, kerohanian, termasuk kawisesan) harus dinaiki/didaki sebagai tanda kesiapan diri untuk menerima ilmu tingkat lanjut yang pastinya lebih tinggi dan berat. Itulah namanya proses menjadi (to be) bukan sekedar memiliki (to have). Dalam konsep pendidikan berdasar kearifan lokal Bali ada istilah, bahwa proses pembelajaran/pendidikan wajib melalui tahapan yang disebut : "bisa, nawang, dadi".

Untuk "bisa" (baca : bise) wajib melajah dengan "teleb" atau "seleg", harus menunjukkan sikap ajeg, enteg, degdeg, tidak boleh ngulurin gedeg apalagi ngredeg dan saling panteg. Dengan modal "bisa" meningkat menjadi "nawang" (mengetahui, memahami dan menguasai), yang seterusnya memuncak pada level “dadi” (nadi), menjadi apa saja sesuai dengan kemampuan/kelebihannya. Setelah berada pada tingkatan "dadi" inilah, diberikan piteket "ajya wera", artinya jangan mabuk, tidak boleh sombong dalam mengemban amanat keilmuan yang telah dikuasai.
Sebab, bagaikan tombak bermata tiga, demikian juga ilmu itu, lebih-lebih ilmu agama (kerohanian/spiritual), dan apalagi ilmu kawisesan ; pertama, bisa menjadi jalan peningkatan kualitas jnana-tattwa guna memperkuat sraddha dan bhakti; kedua jika diterapkan tanpa kendali hati nurani, dapat menjerumuskan pada sifat dan sikap sombong/angkuh yang tentunya membahayakan diri dan juga orang lain; dan ketiga, apa yang telah dipelajari, dipahami dan dikuasai justru tidak akan membawa manfaat apa-apa bagi siapapun, lantaran tanpa internalisasi ke dalam diri, dan juga tidak diimplementssikan bagi kepentingan umat atau masyarakat.

Istilah Balinya, pocol ngelah ilmu (karirihan), sing dadi anggon gena, bilihbilih ten meduwe geginan (rugi mempunyai ilmu, kemampuan, kelebihan, keunggulan atau bahkan kawisesan, lantaran tidak berguna bagi orang lain, lebih-lebih yang bersangkutan tidak memiliki pekerjaan alias pengangguran), tentunya sangat membahayakan, bisa data-data gaene (bisa macam-macam dikerjakan, entah baik ataupun buruk).

Semakin dapat dipahami, menelisik arti adagium "ajya wera" di atas, sesungguhnya mengandung makna sebagai sesanti untuk mana bagi siapapun yang hendak mempelajari apalagi kemudian berhasil menguasai ilmu apapun hendaknya tetap 
bersikap rendah hati. Seperti ilmu padi, semakin berisi sepatutnya bertambah merunduk. Nasihat panglingsir, "de ngaden awak bisa, depang anake ngadanin", jangan merasa diri "bisa, nawang" meskipun sudah "dadi", biarkan orang lain menilai dan mengambil manfaat atas ilmu yang dimiliki. Ilmu itu tidak untuk dipamerkan karena akan menunjukkan keangkuhan atau kesombongan, yang seterusnya dapat menjerumuskan menuju kehancuran, seperti dinyatakan kitab Bhagawadgita, IV. 37 : Yathai 'dhamsi samiddho 'gnir, bhasmasat kurute 'rjuna, jnanagnih sarvakarmani, bhasmasat kurute tatha : bagaikan api menyala, membakar kayu api menjadi abu, Oh Arjuna, api ilmu pengetahuan demikian pula bisa membakar (menghancurkan) segala karma menjadi abu.

\section{PENUTUP}

Konsep "ajya wera", tampaknya sekaligus juga mengingatkan untuk “aja ewere", de ewer, adigag adigung, de degag de ajum, karena akan dapat menyerang balik hingga menghancurkan diri sendiri. Pepatah kuno mengisyaratkan, "menepuk air di dulang”, terkena muka sendiri, akan membuat malu, memalukan bahkan memilukan. Ilmu, entah itu ilmu pengetahuan duniawi, ilmu keagamaan (kerohanian/spiritual), termasuk ilmu kawisesan (yang bersifat magi), sah-sah saja dipelajari, atau bahkan dikuasai, asalkan melalui proses penjenjangan, baik ketika proses pendidikan/pembelajaran berlangsung, setelah berhasil menguasai dan paling penting tatkala diterapkan dalam kehidupan sehari-hari, tidak hanya bermanfaat bagi dirinya, lebih penting lagi untuk keselamatan, kesejahteraan dan kebahagiaan orang lain : gumaweaken sukanikanang wong len.

\section{DAFTAR PUSTAKA}

Antara, Nala, dkk (editor). 2009. Kamus Bali-Indonesia Beraksara Latin Dan Bali. Denpasar:

Badan Pembina Bahasa, Aksara, dan Sastra Bali Provinsi Bali.

Echols, John M., Shadily, Hasan. 2002. Kamus Ingriss-Indonesia, An EnglishIndonesian

Dictionary. Jakarta : PT Gramedia Pustaka Utama

Effendy, Chairil. 2006. "Menegaskan

Kembali Identitas : Menggali Kearifan Lokal dalam

Pengajaran Sastra Lisan”. Makalah dalam Kongres IX Bahasa Indonesia. Jakarta: Pusat Bahasa

Furchan, Arief. 1982. Pengantar Penelitian

Pendidikan. Surabaya : Usaha Nasional Hamidi, 2007.Metode Penelitian dan Teori Komunikasi. Malang. UMM Pres.

Moleong, Lexy J. 2007. Metodologi Penelitian Kualitatif. Bandung. Rosda.

Nasution, S. 1992. Metode Penelitian Naturalistik Kualitatif. Bandung : Tarsito Palmer, Richard E. 1969. Hermeneutics. Evanston Northwestern: Univ. Press. Pohan, Rusdian. 2007. Metodologi Penelitian Pendidikan. Yogyakarta : ArRijal Institute dan Lanarka Publisher 
Pudja. G. 1981. Bhagawadgita (Pancama

Weda). Jakarta : Mayasari.

Poerwadarminta, W.J.S.. 1986. Kamus

Umum Bahasa Indonesia. Jakarta. Balai

Pustaka.

Ritzer, George, Douglas J. Goodman. 2007.

Teori Sosiologi Modern,(Edisi Keenam).

(Alih Bahasa: Alimandan). Jakarta.

Kencana.

Rusman. 2012. Model-Model Pembelajaran,

Mengembangkan Profesionalisme Guru

(Edisi

Kedua). Jakarta: PT RajaGrafindo

Persada

Sugiyono. 2007. Memahami Penelitian

Kuantitatif, Kualitatif dan RD. Bandung :

Alfabeta.

Sumaryono, E. 1999. Hermeneutik Sebuah

Metode Filsafat (Edisi Revisi). Yogyakarta:

Kanisius

Suyadnya, I Gusti Ngurah Made. 2006. Aywa

Wera Dan Pemahamannya. Surabaya:

Paramita

Turaeni, Ni Nyoman Tanjung. 2016. "Mengenal Kearifan Lokal Masyarakat Bali Dalam

Ungkapan Tradisi Lisan

"Wewangsalan". Prosiding Seminar

Nasional Asosiasi Tradisi Lisan.

Denpasar: Pustaka Larasan

Triguna, Ida Bagus Gde Yudha. 2000. Teori Tentang Simbol. Denpasar: Widya Dharma.

Usman, Husaini dan Akbar, Purnomo Setiady. 2008. Metodologi Penelitian Sosial. Jakarta:

PT Bumi Aksara 